\title{
Tandem Mass Spectrometry of Poly(Methacrylic Acid) Oligomers Produced by Negative Mode Electrospray Ionization
}

\author{
Rémi Giordanengo, ${ }^{\text {a }}$ Stéphane Viel, ${ }^{\mathrm{b}}$ Béatrice Allard-Breton, ${ }^{\mathrm{c}}$ \\ André Thévand, ${ }^{\mathrm{a}}$ and Laurence Charles ${ }^{\mathrm{a}}$ \\ a Universités Aix-Marseille I, II \& III-CNRS, UMR 6264: Laboratoire Chimie Provence, Spectrométries \\ Appliquées à la Chimie Structurale, Marseille, France \\ b Université Paul Cézanne-CNRS, UMR 6263: Institut des Sciences Moléculaires de Marseille, Chimiométrie \\ et Spectrométries, Marseille, France \\ c ARKEMA, Centre de Recherche Rhône Alpes, Service Analyse, Pierre-Bénite, France
}

Dissociation of small poly(methyl acrylic acid) (PMAA) anions produced by electrospray was characterized by tandem mass spectrometry. Upon collisional activation, singly, and doubly deprotonated PMAA oligomers were shown to fragment via two major reactions, dehydration and decarboxylation. The elimination of a water molecule would occur between two consecutive acid groups in a charged-remote mechanism, giving rise to cyclic anhydrides, and was shown to proceed as many times as pairs of neutral pendant groups were available. As a result, the number of dehydration steps, together with the abundance of the fragment ions produced after the release of all water molecules, revealed the polymerization degree of the molecule in the particular case of doubly charged oligomers. For singly deprotonated molecules, the exact number of MAA units could be reached from the number of carbon dioxide molecules successively eliminated from the fully dehydrated precursor ions. In contrast to dehydration, decarboxylation reactions would proceed via a charge-induced mechanism. The proposed dissociation mechanisms are consistent with results commonly reported in thermal degradation studies of poly(acrylic acid) resins and were supported by accurate mass measurements. These fragmentation rules were successfully applied to characterize a polymeric impurity detected in the tested PMAA sample. (J Am Soc Mass Spectrom 2009, 20, 25-33) (c) 2009 Published by Elsevier Inc. on behalf of American Society for Mass Spectrometry

$\mathrm{B}$ lock copolymers are of great interest in various research fields. In particular, polymers based on weak acids such as poly(acrylic acid) (PAA) or poly(methacrylic acid) (PMAA) have attracted considerable attention because of the ability of the system to change strongly upon variations in the $\mathrm{pH}$ and ionic strength of the solution [1]. Hydrogels, i.e., weakly cross-linked hydrophilic polymers, obtained after copolymerization of polyethylene glycol (PEG) with methacrylic acid were recently demonstrated to be efficient absorbents of uranyl ions [2]. On the other hand, the ability of amphiphilic PMAA-based block copolymers to self-assemble and produce dynamic micelles sensitive to different stimuli was shown to highly depend on the balance between hydrophobic and hydrophilic segments [3-6]. Since the performance of such copolymer materials is closely associated to structurally related parameters, unambiguous characterization of their microstructure is a crucial analytical issue.

Address reprint requests to Dr. L. Charles, Spectrométries Appliquées à la Chimie Structurale, Campus Saint-Jérôme, Case 511, 13397 Marseille Cedex 20, France. E-mail: laurence.charles@univ-provence.fr
Since the development of soft ionization techniques, mass spectrometry has become a powerful tool to characterize the structure of synthetic polymers. A single MS spectrum can allow the nature of the repeat unit and of the end-groups to be confirmed, or copolymers to be distinguished from homopolymers [7]. As MS allows individual co-oligomer ions to be measured, the overall composition can be determined as long as any peak overlap can efficiently be resolved [8]. MS data could thus indicate the number of each co-monomers but not the position of the repeat units throughout the molecule and distinction of block copolymers from random copolymers requires MS/MS experiments to be performed [9]. Fragmentation pathways along the chain allow the copolymer to be sequenced since each co-monomer shows distinct dissociation behavior. We recently showed that MS/MS dissociation of a poly(ethylene oxide)/polystyrene block copolymer (PEO$b$-PS), synthesized by nitroxide-mediated polymerization (NMP), proceeds by a specific homolytic cleavage of the labile end-group, further allowing a depolymerization process that reveals the PS block size [10].

The first requirement for a useful analysis of copolymer MS/MS data is to understand the fragmentation
(C) 2009 Published by Elsevier Inc. on behalf of American Society for Mass Spectrometry. 1044-0305/09/\$32.00

doi:10.1016/j.jasms.2008.09.019
Published online September 25, 2008 Received May 30, 2008 Revised September 8, 2008 Accepted September 17, 2008 
behavior of homopolymers consisting of each of the co-monomers. Dissociation pathways have been studied for a large variety of polymers, such as PEO [11-24], PS [20, 23-30], or poly (methylmethacrylate) (PMMA) [20, 21, 23, 30-32]. In contrast, few MS studies have been reported for PMAA and most of them focused on the analysis of volatile thermal degradation products of the polymer [33,34]. Intact PMAA oligomer ions could be produced by matrix assisted laser desorption/ionization (MALDI) [35-38]. Although mass averages from these MS data were often biased to low molecular weight and produced with poor signal-to-noise ratios, information regarding absolute masses of each individual macromolecular species was available, allowing monomer and end-group masses to be confirmed. Nonetheless, serious limitations in ionization of such polymers have restricted MS studies to quite low molecular weight molecules $\left(M_{w}<3000\right)$. Moreover, to our knowledge, collision-induced dissociation (CID) or post-source decay (PSD) data have never been reported for PMAA. The aim of this study was thus to establish the MS/MS dissociation pathways of small PMAA oligomers amenable to negative mode electrospray ionization (ESI), to be further used to determine the length of PMAA blocks in PMAA-based copolymers.

\section{Experimental}

\section{Chemicals}

HPLC-grade water and methanol was purchased from SDS (Peypin, France). Poly(methacrylic acid) sodium salt with $M_{w}=1250 \mathrm{~g} / \mathrm{mol}^{-1}$, as determined by gel permeation chromatography (GPC), was purchased from PSS (Mainz, Germany). This PMAA1250 has an H atom as both end-groups. Poly(ethylene glycol)s used for mass internal calibration were from Sigma-Aldrich (St. Louis, MO). All chemicals were used as received without further purification.

\section{Mass Spectrometry}

High-resolution MS and MS/MS experiments were performed with a QStar Elite mass spectrometer (Applied Biosystems SCIEX, Concord, ON, Canada) equipped with an electrospray ionization source operated in the negative ion mode. The capillary voltage was set at $-4200 \mathrm{~V}$ and the cone voltage at $-75 \mathrm{~V}$. In this hybrid instrument, ions were measured using an orthogonal acceleration time-of-flight (TOF) mass analyzer. A quadrupole was used for selection of precursor ions to be further submitted to collision-induced dissociations (CID) in MS/MS experiments. In MS, accurate mass measurements were performed using two reference ions from a poly(ethylene glycol) internal standard, according to a procedure described elsewhere [39]. The precursor ion was used as the reference for accurate measurements of fragment ion $\mathrm{m} / \mathrm{z}$ ratio in
MS/MS spectra. Instrument control, data acquisition and data processing of all experiments were achieved using Analyst software (QS 2.0) provided by Applied Biosystems. Low-resolution $\mathrm{MS}^{3}$ experiments were performed using a 3200 QTRAP mass spectrometer (Applied Biosystems SCIEX) equipped with an electrospray ionization source operated in the negative ion mode (capillary voltage $-4200 \mathrm{~V}$; cone voltage $-50 \mathrm{~V}$ ). The Analyst software (version 1.4.1) provided by Applied Biosystems was used for instrument control, data acquisition and data processing. In both instruments, zero-grade air was used as the nebulizing gas (10 psi) whereas nitrogen was used as the curtain gas ( $20 \mathrm{psi}$ ) as well as the collision gas. Collision energy was set according to the experiments. The studied PMAA1250 was dissolved in water, further diluted using methanol to a final $50 \mathrm{mg} / \mathrm{mL}^{-1}$ concentration and introduced in the ionization source at a $5 \mu \mathrm{L} / \mathrm{min}$ flow rate using a syringe pump.

\section{Nuclear Magnetic Resonance}

All NMR experiments were conducted at $300 \mathrm{~K}$ on a BRUKER AVANCE500 DRX spectrometer operating at $500 \mathrm{MHz}$ for the ${ }^{1} \mathrm{H}$ Larmor frequency, with a Bruker 5 mm triple-resonance ${ }^{1} \mathrm{H} /{ }^{13} \mathrm{C} /{ }^{15} \mathrm{~N}$ cryoprobe optimized for ${ }^{1} \mathrm{H}$ detection and equipped with an actively shielded $z$ gradient coil used for coherence selection. The pulse sequence described previously [40] was used to record the 2D ${ }^{1} \mathrm{H}^{13} \mathrm{C}$ multiplicity edited HSQC experiment shown in Figure 4, by using a heteronuclear coupling constant ${ }^{1} J\left({ }^{1} \mathrm{H}^{13} \mathrm{C}\right)$ of $145 \mathrm{~Hz}$ and an evolution delay of $3.45 \mathrm{~ms}$. This allowed the ${ }^{1} \mathrm{H}_{-}{ }^{13} \mathrm{C}$ HSQC spectrum to be edited by showing the correlations due to $\mathrm{CH} / \mathrm{CH}_{3}$ groups and the $\mathrm{CH}_{2}$ groups as positive and negative, respectively.

\section{Results and Discussion}

\section{ESI-MS Analysis}

Negative mode ESI of PMAA1250 gave rise to a complex mass spectrum where multiple polymeric distributions could be distinguished in the 200 to $1000 \mathrm{~m} / \mathrm{z}$ range (Figure 1). The most intense peaks were from PMAA1250, observed as [PMAA $-\mathrm{H}^{-}$and $[\text { PMAA }-2 \mathrm{H}]^{2-}$ anions, respectively annotated by open and closed circles in Figure 1. A closer inspection of the MS data also revealed that triply charged PMAA1250 molecules were produced with much lower intensity. As doubly deprotonated oligomers were detected from $n=6$ and since the chain length between the two furthest apart carbonyl groups includes 13 carbon atoms in the 6-mer, this result suggest that negative charges must be separated by at least $13 \mathrm{C}$ atoms, i.e., four MAA monomers, to form stable multiply charged species. A very similar result has already been reported for PAA [41]. Singly and doubly deprotonated PMAA 


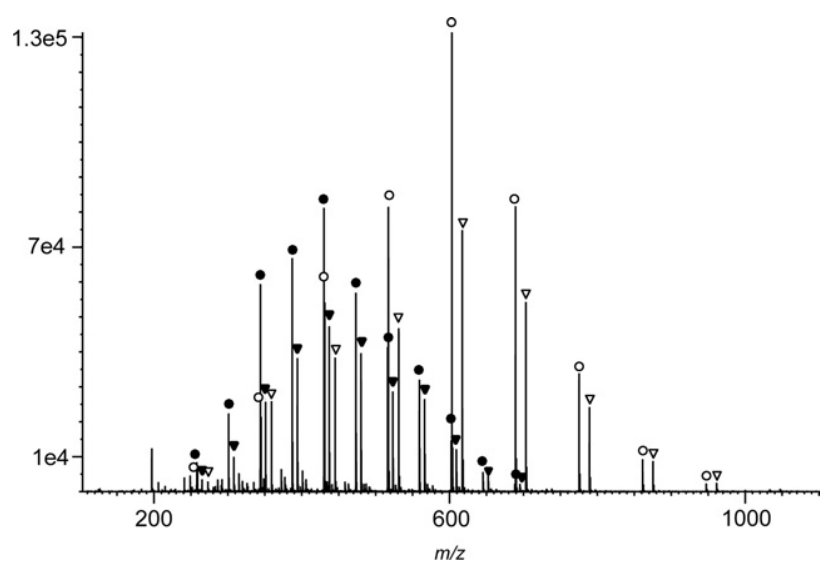

Figure 1. Negative mode ESI-MS spectrum of PMAA1250, detected as [PMAA-H] ${ }^{-}$(open circles) and [PMAA-2H] ${ }^{2-}$ (filled circles). Distributions from an unknown PMAA impurity were also detected at the -1 (open triangles) and -2 (filled triangles) charge states.

oligomers were formed with similar abundance but the $\mathrm{m} / \mathrm{z}$ range of detected signals indicates that these two distributions are different and both less than the expected ones. Weight average molecular masses were calculated to be 612 and $907 \mathrm{~g} / \mathrm{mol}^{-1}$, respectively, for the $1^{-}$and $2^{-}$charge state. Signal-to-noise ratio of $[\mathrm{PMAA}-3 \mathrm{H}]^{3-}$ species was too low for precise average mass calculation but the center of this distribution, measured around $\mathrm{m} / \mathrm{z} 372.5$, also indicates a bias towards low mass oligomers. Such a discrepancy has already been reported for PMAA [35] in both positive and negative mode MALDI, as well as for other acrylic polymers produced in multiple charge states after electrospray ionization [41]. Variation in skimmer cone voltage can cause changes in the relative intensities of the multiple-charge distributions of polymers [42]. However, lowering the cone voltage value from $-75 \mathrm{~V}$ down to $-20 \mathrm{~V}$ did not significantly modify the relative abundance of the different envelopes but mainly alter signal-to-noise ratios.

Two additional intense distributions were found to indicate the presence, in the PMAA1250 sample, of a second polymer detected at two different charge states, $1^{-}$and $2^{-}$, respectively, annotated by open and filled triangles in Figure 1. Compared with the expected polymer, peaks in these distributions were observed with a shift of $14 \mathrm{Da}$. Accurate mass measurements could either suggest a PMAA polymer with a different end-group, i.e., $\mathrm{a}-\mathrm{H},-\mathrm{CH}_{3}$ instead of $-\mathrm{H},-\mathrm{H}$ terminated polymer, or that one of the carboxylic acid groups has been methylated. Replacing methanol by ethanol or acetonitrile in the electrosprayed solution did not affect the observed distribution, indicating that the eventual methylation reaction has not proceeded in the ionization source. Validity of the dissociation rules aimed at being established here will be tested with MS/MS data of this unknown polymeric impurity.

\section{Tandem Mass Spectrometry of Singly Charged Oligomers}

Singly charged precursor ions were first analyzed using collision-induced dissociation. The negative mode ESI-MS/MS spectrum of the PMAA1250 3-mer $(\mathrm{m} / \mathrm{z}$ 259.1), obtained at a $20 \mathrm{eV}$ collision energy (laboratory frame), shows four main fragment ions (Figure 2a). The most intense peak, observed at $\mathrm{m} / \mathrm{z} 241.1$, indicates the elimination of a water molecule from the precursor ion. Water was shown to be one major product in thermal degradation study of PAA [33, 34, 43-45] or PMAA [43]. This dehydration process would occur with the formation of a six-membered ring anhydride from two pendant acid groups (Scheme 1), as previously demonstrated studying thermally degraded PAA and PMAA resins by nuclear magnetic resonance (NMR) [43] or mass spectrometry [33]. The six-membered ring mechanism proposed in Scheme $\mathbf{1}$ to account for the water loss requires two consecutive neutral monomers in the precursor ion. Accurate mass measurements, together
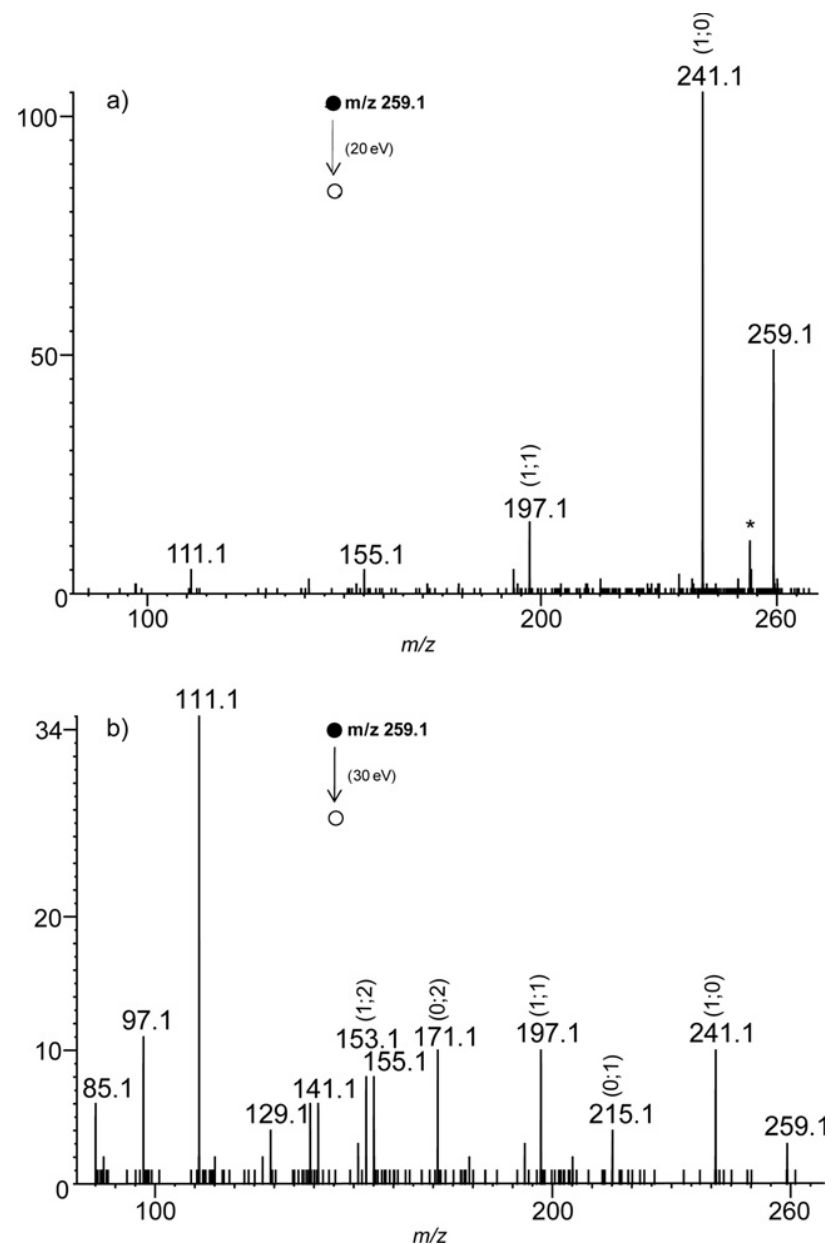

Figure 2. ESI-MS/MS spectra of singly charged PMAA1250 3-mer $(\mathrm{m} / \mathrm{z} 259.1)$ acquired at two collision energies (a) $20 \mathrm{eV}$ and (b) $30 \mathrm{eV}$ (laboratory frame). Peaks annotated by (x;y) result from the elimination of $\mathrm{x}$ water and $\mathrm{y}$ carbon dioxide molecules from the precursor ion. An asterisk indicates a fragment ion of a triply charged precursor ion. 


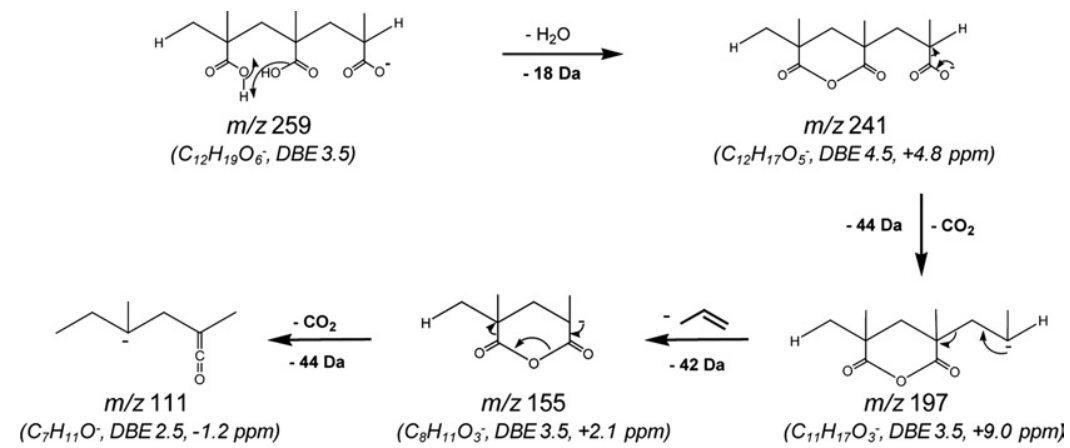

Scheme 1

with $\mathrm{MS}^{3}$ experiments (data not shown), further suggest that the so-formed $\mathrm{m} / \mathrm{z} 241$ fragment ion would decarboxylate to yield $m / z 197$. This reaction could proceed in a charge-induced mechanism, as described in Scheme $\mathbf{1}$. Elimination of a carbon dioxide molecule was systematically found to be a major thermal degradation route for PAA [33, 34, 43-45] and PMAA [43]. All thermal degradation studies also indicate that decarboxylation was slower than dehydration and required higher temperatures to proceed. Interestingly, a similar behavior is observed for gas-phase negatively charged PMAA upon activation. Further dissociation of $\mathrm{m} / z 197$ could occur in a charge-induced mechanism to yield $\mathrm{m} / \mathrm{z} 155$ after elimination of a propene molecule from the oligomer backbone (Scheme 1). Alternatively, elimination of the same neutral could be envisaged from the other side of the molecule, but in such a charge-remote mechanism, two successive proton transfers would be required. In both cases, as the eliminated neutral moiety contains one or the other end-group of the precursor ion, this particular MS/MS reaction would be useful for the determination of unknown oligomer end-groups. Location of the negative charge in $\mathrm{m} / \mathrm{z} 155$ would then allow the six-membered ring to be opened and release a $\mathrm{CO}_{2}$ molecule from the anhydride to yield $\mathrm{m} / \mathrm{z} 111$ (Scheme 1). It should be noted that a peak, annotated with a star in Figure 2a, was observed at $m / z$ 253.1, i.e., a $6 \mathrm{Da}$ difference from the precursor ion, and actually revealed that a triply charged negative ion was selected for fragmentation in the quadrupole analyzer together with the singly deprotonated $\mathrm{m} / \mathrm{z}$ 259.1.

A slight increase in collision energy (from 20 to 30 $\mathrm{eV}$, laboratory frame) in the CID experiment of $\mathrm{m} / \mathrm{z} 259$ largely modifies the MS/MS data, as shown in Figure $2 b$. The five previously described fragments ions are still present but their relative intensities have changed, consistently with the MS/MS filiation described in Scheme 1. In addition, eight new peaks were observed. The fragment ion detected at $m / z 215\left(\mathrm{C}_{11} \mathrm{H}_{19} \mathrm{O}_{4}{ }^{-}\right.$; DBE: 2.5 ; error: $+8.9 \mathrm{ppm}$ ) would indicate the loss of a carbon dioxide molecule from the precursor ion $m / z 259$, as described in Scheme 2. This direct decarboxylation, poorly detected at a $20 \mathrm{eV}$ collision energy, does not appear to proceed at a high rate and would not compete efficiently with the dehydration process, as concluded from thermal degradation studies of neutral PAA and PMAA [33, 34, 43-45]. Location of the negative charge in $m / z 215$ would allow a proton abstraction from one neighbored acidic function, inducing again the loss of carbon dioxide to generate $m / z 171\left(\mathrm{C}_{10} \mathrm{H}_{19} \mathrm{O}_{2}{ }^{-}\right.$; DBE: 1.5; error: $+6.1 \mathrm{ppm})$, as described in Scheme 2 . Further elimination of a propene molecule from $\mathrm{m} / \mathrm{z} 171$ would yield $m / z 129\left(\mathrm{C}_{7} \mathrm{H}_{13} \mathrm{O}_{2}{ }^{-}\right.$; DBE: 1.5 ; error: $\left.-9.3 \mathrm{ppm}\right)$, according to the charged-induced mechanism proposed in Scheme 2. The mass of this lost neutral is expected to vary as a function of the $\omega$ end-group size. As described in Scheme 3, a 1,5-proton transfer in $\mathrm{m} / \mathrm{z} 197$ would result in a bicyclic structure in which delocalization of the negative charge would induce the elimination of a carbon dioxide molecule to form $m / z 153\left(\mathrm{C}_{10} \mathrm{H}_{17} \mathrm{O}^{-}\right.$; DBE 2.5; error: $+4.0 \mathrm{ppm}$ ). This $m / z 153$ fragment ion would further dissociate via a charge-induced mechanism to produce $m / z 97\left(\mathrm{C}_{6} \mathrm{H}_{9} \mathrm{O}^{-}\right.$; DBE: 2.5; error: -14.3 ppm) and a neutral moiety (here, a 2-methylpropene molecule), which would be mass-informative about the $\alpha$ end-group (Scheme 3 ). The only way found to account for the formation of $m / z 141\left(\mathrm{C}_{7} \mathrm{H}_{9} \mathrm{O}_{3}{ }^{-}\right.$; DBE 3.5; error: $+16.2 \mathrm{ppm}$ ) was to consider a different structure for $\mathrm{m} / \mathrm{z}$ 197, as depicted in Scheme 4. This structure implies deprotonation has occurred on the MAA monomer linked to the initiating group; then, after a first dehydration step has occurred, a decarboxylation reaction would have proceeded in a direct mechanism. In such a structural configuration, location of the negative charge near the $\alpha$ end-group would allow the elimination of a 2-methylpropene neutral moiety containing the $-\mathrm{H} \alpha$ end-group. Further dissociation of the so-formed $\mathrm{m} / \mathrm{z}$

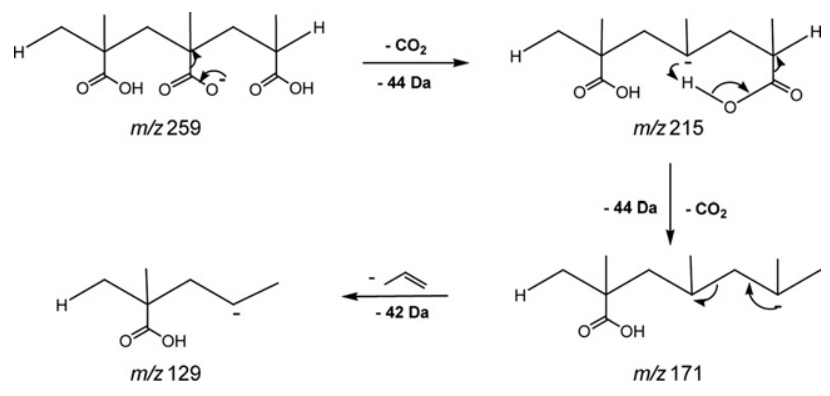

Scheme 2 


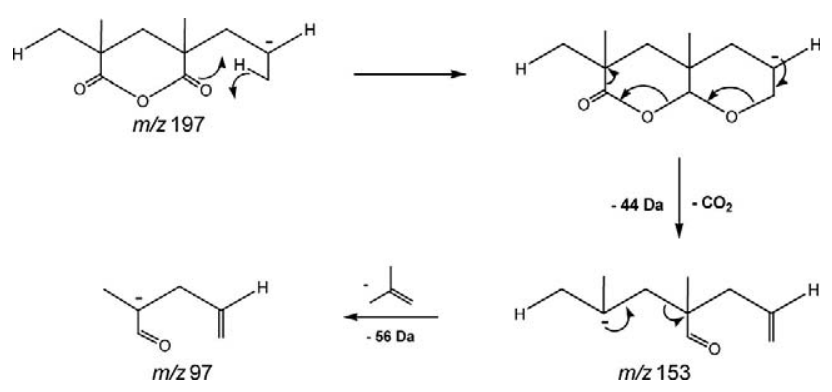

Scheme 3

141 would occur according to two different chargeinduced mechanisms (Scheme 4): elimination of a carbon dioxide molecule would generate $m / z 97\left(\mathrm{C}_{6} \mathrm{H}_{9} \mathrm{O}^{-}\right.$; DBE: 2.5; error: $-14.3 \mathrm{ppm}$ ) whereas elimination of a propene-1-one molecule would produce $\mathrm{m} / \mathrm{z} 85$ $\left(\mathrm{C}_{4} \mathrm{H}_{5} \mathrm{O}_{2}{ }^{-}\right.$; DBE 2.5; error: $\left.+3.5 \mathrm{ppm}\right)$. Finally, the same $\mathrm{m} / \mathrm{z} 197$ fragment ion as described in Scheme 4 would be required to account for the formation of $\mathrm{m} / \mathrm{z} 139$ $\left(\mathrm{C}_{7} \mathrm{H}_{7} \mathrm{O}_{3}{ }^{-}\right.$; DBE 4.5; error: $\left.-10.6 \mathrm{ppm}\right)$. The particular location of the negative charge in this $\mathrm{m} / \mathrm{z} 197$ ion would allow the abstraction of a proton in the 1,5-process depicted in Scheme 5. This rearrangement would then allow the migration of an hydride, via a charge-induced mechanism, and the release of a 2-methylpropane neutral. Further increase of the collision energy did not allow any new fragment ions to be generated.

To account for the formation of some fragment ions, different forms of the precursor ion, i.e., with a different site of deprotonation, had to be envisaged. However, once deprotonation has occurred in the ionization source, all these configurations can be reached from each others since the negative charge can be delocalized via a proton transfer process from one acidic group to the next one. As the size of the precursor ion increases, increasing number of sites are available for charge location and more fragment ions are produced, partic-
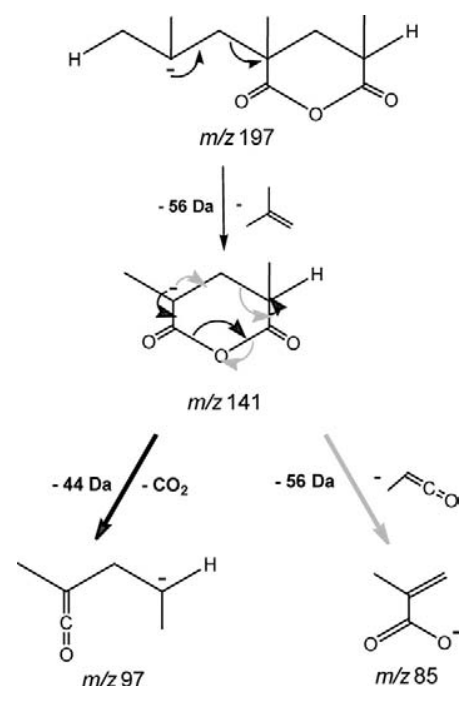

Scheme 4

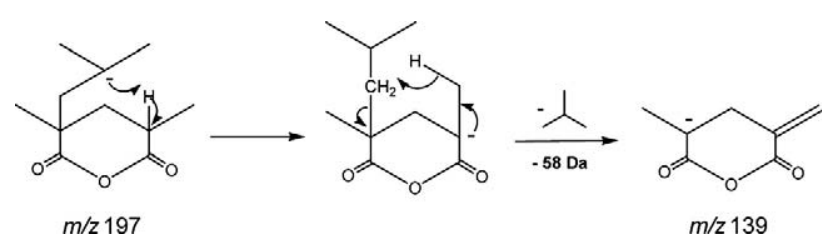

Scheme 5

ularly those arising from cleavages in the backbone. However, intensity of these ions dramatically decreased and any of those reactions which could have been useful for end-group determination were hardly or no longer observed as $n$ increased. Actually, fragment ions arising from water and/or carbon dioxide elimination were found to provide the most clear informative data. First, as $(n-1)$ carboxylic acid groups are available for water elimination in a singly charged $n$-mer, the maximal number of successive $18 \mathrm{Da}$ losses would be equal to $(n-1) / 2$. As a result, the total number of observed water losses in the MS/MS spectra would reveal the exact size of the $n$-mer precursor ion backbone if $\mathrm{n}$ is an odd number, and the number of monomer minus one if $\mathrm{n}$ is an even number. The actual $\mathrm{n}$ value can easily be determined from MS/MS spectra of two consecutive oligomers. For example, as only one dehydration step could be observed in both MS/MS spectra of $\mathrm{m} / \mathrm{z} 259$ (Figure 1) and the next homologue in the distribution $\mathrm{m} / \mathrm{z} 345$ (data not shown), it could be concluded that (1) $\mathrm{m} / \mathrm{z} 259$ contains an odd $\mathrm{n}$ number of MAA monomers and (2) $n=3$. In addition, the number of carbon dioxide eliminations within a given MS/MS filiation for a singly charged $n$-mer was found to be at most equal to $n-1$. Since the number of $\mathrm{H}_{2} \mathrm{O}$ and $\mathrm{CO}_{2}$ elimination were found to be the most relevant reactions in terms of structural characterization, a particular nomenclature (x;y) was adopted for their annotation, where $\mathrm{x}$ and $\mathrm{y}$, respectively, indicate the number of eliminated water and carbon dioxide molecules, as shown in Figure 2.

\section{Tandem Mass Spectrometry of Doubly Charged Oligomers}

The influence of the charge state on MS/MS behavior of PMAA has also been explored. As previously indicated, the main peaks observed in MS/MS spectra of increasing size oligomers arose from elimination of water and carbon dioxide molecules. Since doubly deprotonated PMAA oligomers were formed from $n=6$, losses of $\mathrm{H}_{2} \mathrm{O}$ were the main reactions evidenced in CID spectra of [PMAA $-2 \mathrm{H}]^{2-}$, as exemplified for the 8-mer $(\mathrm{m} / \mathrm{z} 344.1)$ and the 9-mer $(\mathrm{m} / \mathrm{z}$ 387.1 ) in Figure 3. In contrast to MS/MS of singly charged oligomers, ions arising from decarboxylation reactions could only be poorly detected. No other significant fragment ion could be detected at this $20 \mathrm{eV}$ collision energy (laboratory frame). Increase of the collision energy mainly gave rise to low intensity fragment ions in the low $\mathrm{m} / \mathrm{z}$ range. 
As for singly charged molecules, dehydration reactions were found to be of great interest for the structural characterization of doubly charged PMAA oligomers. As oligomers are doubly deprotonated, the number of neutral carboxylic acid groups available for water elimination is equal to $(n-2)$. Therefore, three successive water losses were observed from both the 8-mer and the 9-mer precursor ions submitted to CID, yielding the following MS/MS filiations : $\mathrm{m} / \mathrm{z} 344.1 \rightarrow \mathrm{m} / \mathrm{z} 335.1 \rightarrow$ $m / z 326.1 \rightarrow m / z 317.1$ (Figure 3a) and $m / z 387.1 \rightarrow m / z$ $378.1 \rightarrow m / z 369.1 \rightarrow m / z 360.1$ (Figure 3b). Although the two MS/MS spectra were acquired with the same experimental conditions, that is, with a slightly lower center-of-mass collision energy for $\mathrm{m} / \mathrm{z}$ 387.1, elimination of three water molecules appeared to occur more favorably from the 9-mer compared with the 8-mer. Owing to the fact that three sets of two consecutive neutral MAA monomers (i.e., three pairs) are required to allow elimination of three water molecules, the probability to fulfill this condition in the doubly deprotonated 8-mer was calculated to be equal to:
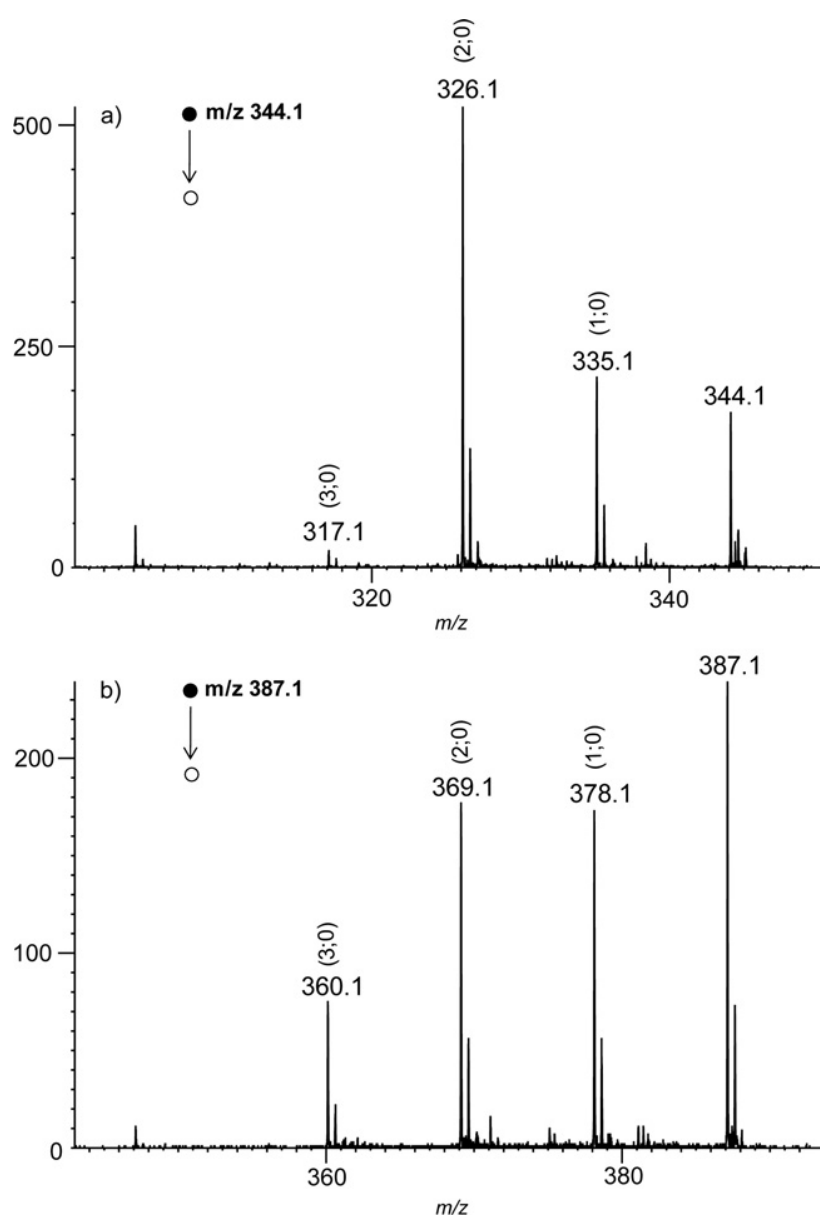

Figure 3. ESI-MS/MS spectrum of doubly charged PMAA1250 (a) 8-mer $(\mathrm{m} / \mathrm{z} 344.1)$ and (b) 9-mer $(\mathrm{m} / \mathrm{z} 387.1)$, acquired at a $30 \mathrm{eV}$ collision energy (laboratory frame). Peaks annotated by (x;y) result from the elimination of $\mathrm{x}$ water and $\mathrm{y}$ carbon dioxide molecules from the precursor ion.

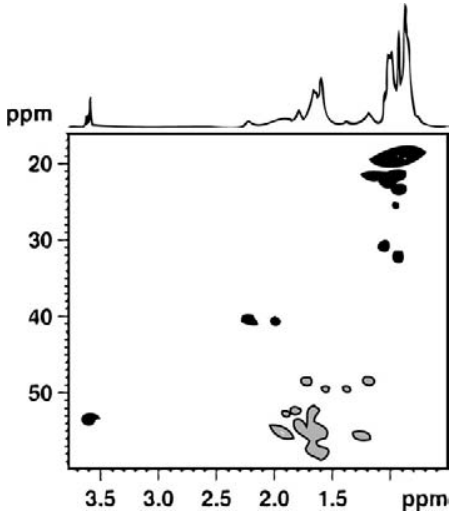

Figure 4. $500 \mathrm{MHz}{ }^{1} \mathrm{H}^{-13} \mathrm{C}$ multiplicity edited HSQC spectrum recorded at $300 \mathrm{~K}$ on a $\mathrm{D}_{2} \mathrm{O}$ solution of PMAA1250 $(20 \mathrm{mg} / \mathrm{mL})$. Positively and negatively phased cross-peaks are shown in black and grey, respectively, and correspond to $\mathrm{CH} / \mathrm{CH}_{3}$ groups (black) and $\mathrm{CH}_{2}$ groups (grey). The corresponding $1 \mathrm{D}^{1} \mathrm{H}$ spectrum is shown at the top. The correlation between the ${ }^{1} \mathrm{H}$ signal at $\delta 3.6 \mathrm{ppm}$ and the ${ }^{13} \mathrm{C}$ signal at $\delta 53 \mathrm{ppm}$ is characteristic of a $\mathrm{OCH}_{3}$ group, which is consistent with the presence in the sample of a polymeric species bearing at least one methoxylated carboxylic group.

$$
\frac{C_{5}^{2}}{C_{8}^{2}}=\frac{10}{28}=35.7 \%
$$

where $C_{8}^{2}$ is the total number of possibilities to arrange 2 charged monomers in a series of 8 and $C_{5}^{2}$ the number of these arrangements which allow neutral monomer pairs to exist. In a doubly deprotonated 9-mer, this probability increases to

$$
\frac{C_{5}^{2} C_{3}^{1}}{C_{9}^{2}}=\frac{30}{36}=83.3 \%
$$

where $C_{3}^{1}$ takes into account the fact that, because there is an odd number of available neutral monomers, isolation of one monomer from the other ones does not affect the potential to form three pairs. Of course, this simple probability calculation has no real physical meaning since all possible arrangements were considered, including the unrealistic ones with two consecutive charged monomers. However, assuming the two negative charges should be separated by at least four MAA monomers to form stable species as concluded from MS data, the probability to fulfill the requirement for three water losses is still higher for the 9 -mer $(9 / 10=90 \%)$ than for the 8 -mer $(3 / 6=50 \%)$. It was not expected that the difference in relative intensity observed between $m / z 317.1$ (Figure 3a) and $m / z 360.1$ (Figure 3b) fits these probability calculations, since relative stability of the various arrangements could not be taken into account. Nevertheless, it can be concluded that the higher relative abundance of $\mathrm{m} / \mathrm{z} 360.1$ would reflect the larger number of possibilities for a doubly deprotonated PMAA 9-mer to eliminate three water molecules, compared with the 8-mer. Although peak intensities change with collision energy, relative intensity of the peak 
annotated $(3 ; 0)$ compared with the peak annotated $(2 ; 0)$ was always found to be higher for the 9-mer than for the 8-mer precursor ion. Therefore, in contrast to singly charged molecules (where the exact number $n$ of MAA monomers could be reached from the maximal number of water losses only in the case of odd values of $n$ ), monitoring the relative intensity of peaks corresponding to maximal dehydration from doubly charged consecutive oligomers would confirm the polymerization degree of these molecules, previously revealed by the study of consecutive oligomer MS/MS spectra (Figure 3).

\section{Microstructural Characterization of the Unknown PMAA}

These dissociation rules were then tested for the unknown PMAA polymer, detected with a 14 Da mass shift compared with the expected polymer in the MS spectrum of PMAA1250. MS/MS data obtained from $m / z 445.2$ (not shown) indicate that the precursor ion could eliminate a water molecule, to produce $m / z$ 427.2, or a methanol molecule, to yield $\mathrm{m} / \mathrm{z}$ 413.2. This last reaction clearly indicates the methylation of one of the carboxylic acid functions. In the MS/MS spectrum, at most one dehydration reaction was observed from the precursor ion as previously mentioned, or from $\mathrm{m} / \mathrm{z}$ 413.2 , i.e., after the release of methanol. Note that the fragment ion formed in the latter reaction, detected at $\mathrm{m} / \mathrm{z} 395.2$, could also arise from the loss of a methanol molecule following dehydration of the precursor ion. These results imply the formation of at most two anhydrides, that is, the presence of at least four neutral monomers, three MAA, and one MMA. Moreover, the observed MS/MS filiation $\mathrm{m} / \mathrm{z} 395 \rightarrow \mathrm{m} / \mathrm{z} 351 \rightarrow \mathrm{m} / \mathrm{z} 307$ $\rightarrow m / z 263$ revealed three successive carbon dioxide eliminations, which is consistent with the presence of two anhydride six-membered rings and one deprotonated MAA monomer. All these dissociation reactions were supported by accurate mass measurements (Table $1)$. Calculating the mass obtained from this combination, as $3 \mathrm{~m}_{\mathrm{MAA}}+\mathrm{m}_{\mathrm{MMA}}+\mathrm{m}_{(\mathrm{MAA}-\mathrm{H})}=443$, indicates the oligomer should be $-\mathrm{H},-\mathrm{H}$-terminated to account for the mass-to-charge ratio of the studied $\mathrm{m} / \mathrm{z} 445$ precursor ion. The chemical composition proposed for

Table 1. Accurate mass measurements obtained for the main fragment ions in the MS/MS spectrum of $m / z 445.2$, a singly charged oligomer from the unknown PMAA distribution

\begin{tabular}{cclcc}
\hline$m / z_{\text {experimental }}$ & $m / z_{\text {theoretical }}$ & Formula & DBE & Error $(p p m)$ \\
\hline \hline 445.2079 & 445.2079 & $\mathrm{C}_{21} \mathrm{H}_{33} \mathrm{O}_{10}^{-}$ & 5.5 & I.S. \\
427.2021 & 427.1973 & $\mathrm{C}_{21} \mathrm{H}_{31} \mathrm{O}_{9}^{-}$ & 6.5 & +11.1 \\
413.1855 & 413.1817 & $\mathrm{C}_{20} \mathrm{H}_{29} \mathrm{O}_{9}^{-}$ & 6.5 & +9.2 \\
395.1736 & 395.1711 & $\mathrm{C}_{20} \mathrm{H}_{27} \mathrm{O}_{8}^{-}$ & 7.5 & +6.2 \\
351.1831 & 351.1813 & $\mathrm{C}_{19} \mathrm{H}_{27} \mathrm{O}_{6}^{-}$ & 6.5 & +5.1 \\
307.1907 & 307.1914 & $\mathrm{C}_{18} \mathrm{H}_{27} \mathrm{O}_{4}^{-}$ & 5.5 & -2.5 \\
263.2082 & 263.2016 & $\mathrm{C}_{17} \mathrm{H}_{27} \mathrm{O}_{2}^{-}$ & 4.5 & +24.9 \\
\hline
\end{tabular}

I.S. = internal standard. $m / z 445$ was further confirmed by MS/MS data obtained for the next homologue in the distribution, that is $m / z 531$, which was shown to experience (1) elimination of one water molecule followed by the loss of one methanol neutral, (2) methanol loss before water elimination, and (3) two successive water losses. CID of the corresponding oligomer with no MMA unit, i.e., the unmodified PMAA 5-mer at $m / z$ 431, revealed two successive water losses from the precursor ion, ultimately leading to the same $m / z 395$ fragment ion as observed in MS/MS spectra of $m / z 445$ (Table 1). Doubly charged oligomers from this unknown polymer were also selected for dissociation (data not shown). For example, formation of up to three anhydrides was revealed by elimination of two molecules of water and one molecule of methanol from the $\mathrm{m} / \mathrm{z} 351.1$ precursor ion. It could thus be concluded from these readily available data that the oligomer ion submitted to CID was the doubly deprotonated form of $\mathrm{H}-(\mathrm{MAA})_{7^{-}}$ (MMA) $)_{1}-\mathrm{H}$. It should be noted that although the collision energy was raised, only three of the five possible decarboxylation reactions were observed, indicating again that the number of successive $\mathrm{CO}_{2}$ eliminations is not a reliable information for microstructural characterization of doubly charged PMAA oligomers. MS/MS data from $m / z$ 394.1, the next homologue of $m / z 351.1$ in the doubly charged oligomer distribution, also indicated the formation of three anhydrides, after the precursor ion has dehydrated twice and eliminated a methanol molecule. However, the value obtained while calculating the intensity ratio of the fragment ion containing three anhydride groups versus the most intense fragment ion with two anhydrides was found to be three times larger in the case of $m / z 394.2$ compared to $m / z$ 351.1. As discussed previously, this result would reflect the larger number of possibilities to arrange three pairs of neutral monomers in $m / z$ 394.2, indicating this ion is the doubly deprotonated form of $\mathrm{H}-(\mathrm{MAA})_{8}$ $(\mathrm{MMA})_{1}-\mathrm{H}$. These MS/MS findings were further validated by NMR experiments which are consistent with the presence of a polymeric species containing at least one methylated carboxylic acid (Figure 4). However, the position of the MMA unit within the PMAA chain could not be determined. Indeed, this information could have been reached from cleavages of the intact oligomer backbone but, when observed, these reactions were shown to proceed from fragment ions in which most of the pendant groups have already formed cyclic anhydrides.

\section{Conclusions}

Negative mode electrospray ionization tandem mass spectrometry was shown to be an efficient tool to determine the number of repeat units in PMAA oligomers. A straightforward way to reach the molecule polymerization degree consists of monitoring the number of dehydration and/or decarboxylation steps in the MS/MS spectra. Depending on the precursor ion charge 
state, one of these two major dissociation routes should be studied. Because minor fragmentation reactions consisting of polymer backbone cleavages were hardly observed as the oligomer size increased, they could not be useful for end-group determination. These dissociation rules were established to be further used to characterize the microstructure of PMAA-based copolymers. However, negative mode ionization might not always be efficient for copolymers. Particularly, ionization of polymers containing hydrophobic segments is expected to preferentially occur via cationic adduction. Characterization of the MS/MS behavior of PMAA ions produced in positive mode electrospray is thus required and is currently under study in our laboratory.

\section{Acknowledgments}

The authors thank ARKEMA for their financial support. R.G. thanks Arkema for their 3-year grant. L.C. acknowledges support from Spectropole, the Analytical Facility of Aix-Marseille University, by allowing special access to the instruments purchased with European funding (FEDER OBJ2142-3341).

\section{References}

1. Forster, S.; Abetz, V.; Muller, A. H. E. Polyelectrolyte Block Copolymer Micelles. In Polyelectrolytes with Defined Molecular Architecture II, Vol. CLXVI, Schmidt, M., Ed.; Lavoisier: Paris, France, 2004; pp 173-210.

2. Mun, G. A.; Nurkeeva, Z. S.; Irmukhametova, G. S.; Guven, O. Synthesis, Characterization, and Adsorption Study of the Uranyl Ions by Hydrogels Based on Polyethylene Glycol and Methacrylic Acid Copolymers. Nucl. Instrum. Methods Phys. Res. Sect. B 2007, 265, 379-384.

3. Colombani, O.; Ruppel, M.; Schubert, F.; Zettl, H.; Pergushov, D. V.; Muller, A. H. E. Synthesis of Poly(n-Butyl Acrylate)-Block-Poly(Acrylic Acid) Diblock Copolymers by ATRP and Their Micellization in Water. Macromolecules 2007, 40, 4338-4350.

4. Colombani, O.; Ruppel, M.; Burkhardt, M.; Drechsler, M.; Schumacher, M.; Gradzielski, M.; Schweins, R.; Muller, A. H. E. Structure of Micelles of Poly(n-Butyl Acrylate)-Block-Poly (Acrylic Acid) Diblock Copolymers in Aqueous Solution. Macromolecules 2007, 40, 4351-4362.

5. Burkhardt, M.; Martinez-Castro, N.; Tea, S.; Drechsler, M.; Babin, I.; Grishagin, I.; Schweins, R.; Pergushov, D. V.; Gradzielski, M.; Zezin A. B.; Muller, A. H. E. Polyisobutylene-Block-Poly(Methacrylic Acid) Diblock Copolymers: Self-Assembly in Aqueous Media. Langmuir 2007, 23, 12864-12874.

6. Pergushov, D. V.; Remizova, E. V.; Feldthusen, J.; Zezin, A. B.; Muller, A. H. E.; Kabanov, V. A. Novel Water-Soluble Micellar Interpolyelectrolyte Complexes. J. Phys. Chem. B 2003, 107, 8093-8096.

7. Montaudo, M. S. Mass Spectra of Copolymers. Mass Spectrom. Rev. 2002, $21,108-144$.

8. Koster, S.; Duursma, M. C.; Boon, J. J.; Nielen, M. W. F.; de Koster, C. G.; Heeren, R. M. A. Structural Analysis of Synthetic Homo- and Copolyesters by Electrospray Ionization on a Fourier Transform Ion Cyclotron Resonance Mass Spectrometer. J. Mass Spectrom. 2000, 35, 739-748.

9. Jackson, A. T.; Scrivens, J. H.; Williams, J. P.; Baker, E. S.; Gidden, J.; Bowers, M. T. Microstructural and Conformational Studies of Polyether Copolymers. Int. J. Mass Spectrom. 2004, 238, 287-297.

10. Girod, M.; Phan, T. N.; Charles, L. Microstructural Study of A NitroxideMediated Poly(Ethylene Oxide)/Polystyrene Block Copolymer (PEO-b-PS) by Electrospray Tandem Mass Spectrometry. J. Am. Soc. Mass Spectrom. 2008, 19, 1163-1175.

11. Lattimer, R. P. Tandem Mass-Spectrometry of Lithium-Attachment Ions from Polyglycols. I. Am. Soc. Mass Spectrom. 1992, 3, 225-234.

12. Lattimer, R. P. Tandem Mass-Spectrometry of Poly(Ethylene Glycol) Lithium-Attachment Ions. J. Am. Soc. Mass Spectrom. 1994, 5, 1072-1080.

13. Botrill, A. R.; Giannakopulos, A. E.; Millichope, A.; Lee, K. S.; Derrick, P. J. Combination of Time-of-Flight Mass Analyzers with MagneticSector Instruments: In-Line and Perpendicular Arrangements. Applications to Poly(Ethylene Glycol) with Long-Chain End Groups. Eur. J. Mass Spectrom. 2000, 6, 225-232.

14. Bottrill, A. R.; Giannakopulos, A. E.; Waterson, C.; Haddleton, D. M.; Lee, K. S.; Derrick, P. J. Determination of End Groups of Synthetic Polymers by Matrix-Assisted Laser Desorption/Ionization: HighEnergy Collision-Induced Dissociation. Anal. Chem. 1999, 71, 36373641 .

15. Chen, R.; Li, L. Lithium and Transition Metal Ions Enable Low Energy Collision-Induced Dissociation of Polyglycols in Electrospray Ionization Mass Spectrometry. J. Am. Soc. Mass Spectrom. 2001, 12, 832-839.
16. Chen, R.; Yu, X. L.; Li, L. Characterization of Poly(Ethylene glycol) Esters Using Low Energy Collision-Induced Dissociation in Electrospray Ionization Mass Spectrometry. J. Am. Soc. Mass Spectrom. 2002, 13, 888-897.

17. Girod, M.; Carissan, Y.; Humbel, S.; Charles, L. Tandem Mass Spectrometry of Doubly Charged Poly(Ethylene Oxide) Oligomers Produced by Electrospray Ionization. Int. J. Mass Spectrom. 2008, 272, 1-11.

18. Hoteling, A. J.; Kawaoka, K.; Goodberlet, M. C.; Yu, W. M.; Owens, K. G. Optimization of Matrix-Assisted Laser Desorption/Ionization Time-of-Flight Collision-Induced Dissociation Using Poly(Ethylene Glycol). Rapid Commun. Mass Spectrom. 2003, 17, 1671-1676.

19. Jackson, A. T.; Green, M. R.; Bateman, R. H. Generation of End-Group Information from Polyethers by Matrix-Assisted Laser Desorption/ Ionization Collision-Induced Dissociation Mass Spectrometry. Rapid Commun. Mass Spectrom. 2006, 20, 3542-3550.

20. Jackson, A. T.; Williams, J. P.; Scrivens, J. H. Desorption Electrospray Ionization Mass Spectrometry and Tandem Mass Spectrometry of Low Molecular Weight Synthetic Polymers. Rapid Commun. Mass Spectrom. 2006, 20, 2717-2727.

21. Jackson, A. T.; Yates, H. T.; Scrivens, J. H.; Critchley, G.; Brown, J.; Green, M. R.; Bateman, R. H. The Application of Matrix-Assisted Laser Desorption/Ionization Combined with Collision-Induced Dissociation to the Analysis of Synthetic Polymers. Rapid Commun. Mass Spectrom. 1996, 10, 1668-1674.

22. Okuno, S.; Kiuchi, M.; Arakawa, R. Structural Characterization of Polyethers Using Matrix-Assisted Laser Desorption/Ionization Quadrupole Ion Trap Time-of-Flight Mass Spectrometry. Eur. J. Mass Spectrom. 2006, 12, 181-187.

23. Hoteling, A. J.; Owens, K. G. Improved PSD and CID on a MALDI-TOF MS. J. Am. Soc. Mass Spectrom. 2004, 15, 523-535.

24. Pastor, S. J.; Wilkins, C. L. Sustained Off-Resonance Irradiation and Collision-Induced Dissociation for Structural Analysis of Polymers by MALDI-FT-MS. Int. J. Mass Spectrom. 1998, 175, 81-92.

25. Gies, A. P.; Vergne, M. J.; Orndorff, R. L.; Hercules, D. M. MALDI-TOF/ TOF CID Study of Polystyrene Fragmentation Reactions. Macromolecules 2007, 40, 7493-7504.

26. Jackson, A. T.; Bunn, A.; Hutchings, L. R.; Kiff, F. T.; Richards, R. W.; Williams, J.; Green, M. R.; Bateman, R. H. The Generation of End Group Information from Poly(Styrene)s by Means of Matrix-Assisted Laser Desorption/Ionization-Collision Induced Dissociation. Polymer 2000, 41, 7437-7450.

27. Jackson, A. T.; Yates, H. T.; Scrivens, J. H.; Green, M. R.; Bateman, R. H. Matrix-Assisted Laser Desorption/Ionization-Collision Induced Dissociation of Poly(Atyrene). J. Am. Soc. Mass Spectrom. 1998, 9, 269-274.

28. Polce, M. J.; Ocampo, M.; Quirk, R. P.; Wesdemiotis, C. Tandem Mass Spectrometry Characteristics of Silver-Cationized Polystyrenes: Backbone Degradation Via Free Radical Chemistry. Anal. Chem. 2008, 80, 347-354.

29. Polce, M. J.; Ocampo, M.; Quirk, R. P.; Leigh, A. M.; Wesdemiotis, C Tandem Mass Spectrometry Characteristics of Silver-Cationized Polystyrenes: Internal Energy, Size, and Chain End Versus Backbone Substituent Effects. Anal. Chem. 2008, 80, 355-362.

30. Scrivens, J. H.; Jackson, A. T.; Yates, H. T.; Green, M. R.; Critchley, G. Brown, J.; Bateman, R. H.; Bowers, M. T.; Gidden, J. The Effect of the Variation of Cation in the Matrix-Assisted Laser Desorption/Ionization Collision Induced Dissociation (MALDI-CID) Spectra of Oligomeric Systems. Int. J. Mass Spectrom. 1997, 165/166, 363-375.

31. Jackson, A. T.; Slade, S. E.; Scrivens, J. H. Characterization of Poly(Alkyl Methacrylate)s by Means of Electrospray Ionization-Tandem Mass Spectrometry (ESI-MS/MS). Int. J. Mass Spectrom. 2004, 238, 265-277.

32. Jackson, A. T.; Yates, H. T.; Scrivens, J. H.; Green, M. R.; Bateman, R. H. Utilizing Matrix-Assisted Laser Desorption/Ionization-Collision Induced Dissociation for the Generation of Structural Information from Poly(Alkyl methacrylates). J. Am. Soc. Mass Spectrom. 1997, 8, 1206-1213.

33. Lattimer, R. P. Pyrolysis Mass Spectrometry of Acrylic Acid Polymers. J. Anal. Appl. Pyrolysis 2003, 68/69, 3-14.

34. Maurer, J. I.; Eustace, D. J.; Ratcliffe, C. T. Thermal Characterization of Poly(Acrylic Acid). Macromolecules 1987, 20, 196-202.

35. Wyatt, M. F.; Schaeffer, N.; Tan, B.; Cooper, A. I. Strategies for the Analysis of Poly(Methacrylic Acid) by Matrix-Assisted Laser Desorption/ Ionization Time-of-Flight Mass Spectrometry. J. Am. Soc. Mass Spectrom. 2007, 18, 1507-1510.

36. Saito, R.; Yamaguchi, K. Synthesis of Cyclic Methacrylic Acid Oligomers by Atom Transfer Radical Polymerization. J. Polym. Sci. Part A Polym. Chem. 2005, 43, 6262-6271.

37. Saito, R.; Kobayashi, H. Synthesis of Polymers by Template Polymerization. 2. Effects of Solvent and Polymerization Temperature. Macromolecules 2002, 35, 7207-7213.

38. Burkoth, A. K.; Anseth, K. S. MALDI-TOF Characterization of Highly CrossLinked, Degradable Polymer Networks. Macromolecules 1999, 32, 1438-1444.

39. Charles, L. Influence of Internal Standard Charge State on the Accuracy of Mass Measurements in Orthogonal Acceleration Timeof-Flight Mass Spectrometers. Rapid Commun. Mass Spectrom. 2008, 22, 151-155.

40. Willker, W.; Leibfritz, D.; Kerssebaum, R.; Bermel, W. Gradient Selection in Inverse Heteronuclear Correlation Spectroscopy. Magn. Reson. Chem. 1993, 31, 287-292.

41. Leenheer, J. A.; Rostad, C. E.; Gates, P. M.; Furlong, E. T.; Ferrer, I. Molecular Resolution and Fragmentation of Fulvic Acid by Electrospray 
Ionization/Multistage Tandem Mass Spectrometry. Anal. Chem. 2001, 73, 1461-1471.

42. Hunt, S. M.; Sheil, M. M.; Belov, M.; Derrick, P. J. Probing the Effects of Cone Potential in the Electrospray Ion Source: Consequences for the Determination of Molecular Weight Distributions of Synthetic Polymers. Anal. Chem. 1998, 70, 1812-1822.

43. Fyfe, C. A.; McKinnon, M. S. Investigation of the Thermal-Degradation of Poly(Acrylic Acid) and Poly(Methacrylic Acid) by High-Resolution
C-13 CP/MAS NMR-Spectroscopy. Macromolecules 1986, 19 1909-1912.

44. McNeill, I. C.; Sadeghi, S. M. T. Thermal-Stability and Degradation Mechanisms of Poly(Acrylic Acid) and Its Salts. 1. Poly(Acrylic Acid). Polym. Degrad. Stab. 1990, 29, 233-246.

45. Otsu, T.; Quach, L. Head-to-Head Vinyl-Polymers. 3. Preparation and Characterization of Head-to-Head Poly(Acrylic Acid) and Its Esters. Polym. Sci. Part A Polym. Chem. s1981, 19, 2377-2389. 